\title{
Oxidative stress and prostatic diseases (Review)
}

\author{
THIERRY ROUMEGUÈRE ${ }^{1,2}$, JOSEPH SFEIR $^{3}$, ELIE EL RASSY $^{4}$, SIMONE ALBISINNI $^{1}$, \\ PIERRE VAN ANTWERPEN ${ }^{2}$, KARIM ZOUAOUI BOUDJELTIA ${ }^{2}$, \\ NASSIM FARÈS ${ }^{5}$, JOSEPH KATTAN $^{4}$ and FOUAD AOUN ${ }^{3,6}$ \\ ${ }^{1}$ Department of Urology, University Clinics of Brussels, Université Libre de Bruxelles, Erasme Hôpital, 187793 Bruxelles; \\ ${ }^{2}$ Laboratory of Experimental Medicine, Unit 222, Université Libre de Bruxelles, Le Centre Hospitalier Universitaire de Charleroi, \\ 6042 Charleroi, Belgium; Departments of ${ }^{3}$ Urology and ${ }^{4}$ Oncology, Hôtel-Dieu de France University Hospital, \\ Faculty of Medicine, Saint Joseph University; ${ }^{5}$ Research Laboratory of Physiology and PathoPhysiology, \\ Faculty of Medicine, Saint Joseph University, Beirut 166830, Lebanon; ${ }^{6}$ Department of Urology, \\ Jules Bordet Institute, Université Libre de Bruxelles, 1000 Bruxelles, Belgium
}

Received April 11, 2017; Accepted August 18, 2017

DOI: $10.3892 / \mathrm{mco} .2017 .1413$

\begin{abstract}
Prostatic diseases are a common health problem among males in Western countries, and include chronic prostatic diseases, which have an unclear pathogenesis and few treatment options. In vitro and in vivo studies describe oxidative stress as a major pathway involved in the occurrence of benign prostatic hyperplasia, prostatic cancer and chronic prostatitis. Thus, the oxidative stress cascade is a potential target for the treatment of prostatic diseases. This paper presents a systematic review of the available data concerning the association between oxidative stress and the most common chronic prostatic diseases, and describes the available treatment options that act upon this pathway.
\end{abstract}

\section{Contents}

1. Introduction

2. Methodology and evidence acquisition

3. Evidence synthesis

4. Conclusion

\section{Introduction}

Prostatic disease is a common health problem among males in Western countries and has a marked impact on the quality of life of aging males (1). Prostate cancer (PCa) is the most preva-

Correspondence to: Dr Elie El Rassy, Department of Oncology, Hôtel-Dieu de France University Hospital, Faculty of Medicine, Saint Joseph University, Adib Ishaac Street, Beirut 166830, Lebanon E-mail: elie.rassy@hotmail.com

Key words: oxidative stress, reactive oxygen species, prostate, prostate cancer, benign prostatic hyperplasia lent cancer type in males $>50$ years of age and the second most common cause of cancer-associated mortality in males (2). Benign prostatic hyperplasia (BPH) represents the most common urologic disorder among elderly men, with $40 \%$ of males $>60$ years affected (3). Chronic prostatitis/chronic pelvic pain syndromes (CP/CPPS) are other challenging urology disorders responsible for considerable disability in affected patients (4). The majority of these prostatic disorders are age-associated and epidemiologically linked. The presence of functioning Leydig cells of the testes and good 5- $\alpha$-reductase activity are essential for the development of these conditions (5). Their pathogenesis is multifactorial, involving several factors, including genetic instability, inflammation, endocrine disruptors, atherosclerosis, hormones and oxidative stress (5). The integration of these factors in a well-defined pathogenic process from the initiation, development and progression of the abovementioned prostatic conditions has not been attained to date. Oxidative stress is among the possible mechanisms that may account for chronic prostatic disorders. In this paper, a systematic review of the role of oxidative stress in chronic prostatic disorders was conducted and the emerging treatments that target this pathogenesis are discussed.

\section{Methodology and evidence acquisition}

A systematic review of the literature available online was conducted in March 2016 using the following keywords: 'Oxidative stress' and 'prostate'. Searches for relevant original articles, clinical studies and research papers published since January 2000 were performed using the Cochrane Library Database, PubMed and MEDLINE. The authors manually reviewed the significant results and citations. The Preferred Reporting Items for Systematic Reviews and Meta-Analyses process for reporting included and excluded studies was followed; the flowchart in Fig. 1 lists the numbers of papers identified and then included or excluded at each stage. Studies reported in English and presenting data regarding the measurement of oxidative stress in patients with BPH, PCa or $\mathrm{CP} / \mathrm{CPPS}$ were included. Animal studies and in vitro models 
were also included. Review articles and articles published in languages other than English were excluded.

\section{Evidence synthesis}

Oxidative stress and $\mathrm{BPH}$. The etiology and pathogenesis of $\mathrm{BPH}$, a common disease in aging males, remain to be elucidated. Several parameters and signaling pathways have been suggested to serve a role in prostatic growth, but there is no integrative theory to explain the interaction among all these mediators. Recently, it has been revealed that CP may directly induce prostatic proliferation of stromal and glandular cells via the production of reactive oxygen species (ROS), leading to prostatic tissue damage and vascular injury $(6,7)$. Oxidative stress damage to the prostatic tissue is not only limited to the structure and function of the proteins, but also to alterations in the DNA repair machinery and post-translational modifications (8).

Direct toxicity of oxidative stress in BPH. Oxidative DNA damage results in point mutations, deletions or rearrangements and contributes to a change in the normal regulation of programmed cell death, thereby leading to hyperplastic or precancerous transformation (9). The rapid prostatic cell turnover in human prostate tissue and the paucity of DNA repair enzymes contribute to the particular vulnerability of the prostatic gland to oxidative stress (9). However, the molecular mechanisms leading to chronic inflammation, $\mathrm{BPH}$ and malignant transformation are not well understood. NF- $\mathrm{kB}$, a transcriptional factor that regulates inflammation, immune response, cell proliferation, cell migration and apoptosis, has been recently studied (10). ROS have been revealed to stimulate NF- $\mathrm{KB}$ by activating the NF- $\mathrm{KB}$-inducing kinase (NIK) and TNF- $\alpha / \mathrm{AP}-1$ transduction pathways, thus leading to the occurrence of CP. NF- $\mathrm{\kappa B}$ can also induce loss of imprinting of insulin-like growth factor 2 in both cancerous and noncancerous human prostate cells. Consequently, it was proposed that NF- $\mathrm{KB}$ modulation may prevent oxidative stress-induced alterations in the epigenome.

Apart from the direct effect of oxidative stress on DNA, ROS can also be indirectly genotoxic (11). ROS can initiate autocatalytic lipid peroxidation that generates several genotoxic breakdown products, including peroxyl radicals, alkoxyl radicals and aldehydes, such as malondialdehyde (11). In contrast to free radicals, these aldehydes can diffuse out of the cell and reach distant targets. The measurement of circulating malondialdehyde levels in plasma or serum provides a non-invasive method of estimating the oxidative stress level and can be used as a biomarker to examine lipid peroxidation-mediated disorders. Plasma peroxide levels and lipid peroxidation were significantly increased in patients with BPH compared with controls (12-14). However, studies of circulating malondialdehyde levels in associated with BPH have produced contradictory results $(12,15)$.

In $\mathrm{BPH}, 8-\mathrm{OH}$ deoxyguanosine $(\mathrm{dG})$ is a marker of oxidative DNA damage. Quantitative analysis of this marker revealed increased levels in the epithelial cells of BPH, as compared with in the normal transition zone (15). NADPH oxidase 4 (NOX4) has also been studied as a member of a family of proteins that generate ROS in mice; the NOX4 transgenic mice exhibited increased levels of 8-OH dG (15). During the course of the study, increased prostate weight was noted through epithelial proliferation and stromal alterations, such as fibrosis (16).

Modulation of oxidative stress in BPH. Oxidative stress in BPH is primarily modulated by angiotensin II (Ang II) and myeloperoxidase (MPO). Ang II is the main effector peptide of the renin angiotensin system (RAS) and exerts a variety of biological actions, including NOX activation, stimulation of cell growth and migration, and the inflammation of smooth muscle cells and fibroblasts $(17,18)$. Increased Ang II specific activity has been reported in patients suffering from BPH (19).

MPO is a member of the peroxidase superfamily that is stored within the azurophilic granules of neutrophils and monocytes (20). MPO is responsible for the formation of hypochlorous acid, a strong oxidant agent that generates modified oxidized lipoproteins (Mox-LDL) (20). MPO is released in the extracellular medium in response to high levels of cytokines, promotes oxidative damage to the host tissue and activates procarcinogens (21). MPO is present in prostatic epithelial cells; however, its role in the various chronic prostatic disorders has not yet been elucidated (22). MPO and Ang II interact in the bloodstream to produce Mox-LDLs, which then promote the release of IL- 8 and TNF- $\alpha$ by endothelial cells and monocytes, respectively (23).

\section{Oxidative stress and $P C a$}

Direct toxicity of oxidative stress in PCa. Oxidative stress contributes to epigenetic alterations that may ultimately lead to the development of cancer. Oxidative stress has been demonstrated to increase during carcinogenesis, and the activity of certain genes that serve an antioxidant role also increases. $\mathrm{NAD}(\mathrm{P}) \mathrm{H}$ :quinoneoxidoreductase 1 (NQO1) is a cytoprotective enzyme that acts as a genome protector of DNA alterations secondary to oxidative stress (24). NQO1 knockdown increases IL-8, which in turn decreases $\mathrm{p} 53$ and activates NF- $\mathrm{kB}$ to mediate cell survival (25). NF- $\mathrm{KB}$ promotes cancer progression in castration-resistant $\mathrm{PCa}$ (CRPC) through spermidine/spermine $\mathrm{N}$-acetyltransferase (SSAT) via the effect of androgens (26). $\mathrm{NF}-\mathrm{\kappa B}$ also alters the regulation of IGF2 imprinting by downregulating CCCTC-binding factor (CTCF) (27).

Modulation of oxidative stress in PCa. Tumorigenesis may also result from the deregulation of oxidative stress responses (28). Oxidative stress may contribute to an increase in cell viability and resistance to stress by upregulating ERp57 (29). Oxidative stress increases the transcription factors for certain cancer survival proteins, including Hsp27 and PRDX6, thus protecting PCa cells from necrosis induced by oxidative stress (29). ROS induce carcinogenesis by increasing STAMP2 expression via the ATF4 gene. STAMP2 subsequently increases ROS through its iron reductase activity (30).

Oxidative stress-induced DNA mutations with secondary genomic instability causing carcinogenesis have been attributed in part to the epigenetic silencing of glutathione S-transferase $\pi$ (GSTP1) and catalase deficiency $(31,32)$. Other mutations have also been associated with cancer progression. Testicular nuclear receptor 4 (TR4) serves protective roles against oxidative stress and DNA damage; however, the association between TR4 and tumor progression remains 


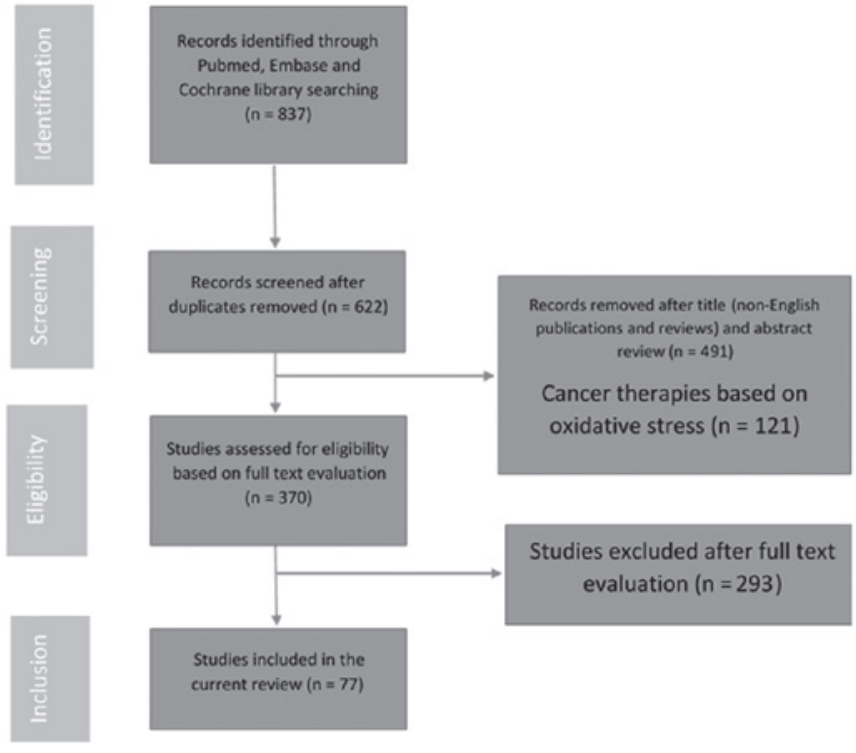

Figure 1. Flow chart illustrating the article selection process for the present review.

unclear. TR4 is associated with the Gleason score of PCa via the promotion of CCL2/CCR2 signaling, thus promoting the deregulation of oxidative scavengers under chronic inflammation $(33,34)$. In human PCa, post-translational modifications are induced by redox imbalances, including the oxidation of thioredoxin 1, sulfinylation of peroxiredoxins, and the nitration and methylation of manganese superoxide dismutase (35).

Several studies have suggested the role of oxidative stress in causing mitochondrial DNA mutations, which may lead to genetic and epigenetic alterations in the nucleus and are thus involved in carcinogenesis $(36,37)$. The glutathione S-transferase (GST) gene superfamily (A, M, T and P gene classes) encodes a group of enzymes that protect the DNA from oxidative damage. Polymorphisms in these genes have been thoroughly studied, and the current evidence does not suggest any effect on the risk for PCa (38). This finding may be explained by the fact that carcinogens whose effect is modifiable by GST minimally contribute to carcinogenesis (38).

GPx4 has been suggested to be one of the selenoproteins that serve a role against ROS-induced lipid peroxidation. Knock-out mice for the gene producing GPx4 express high levels of the proliferation indicator $\mathrm{Ki}-67$ and specific markers of pro-oncogenic pathway activation, such as pS6 and pMAPK (39). Jones et al (40) investigated the role of the chemokine receptor Cysteine-X-C Receptor 4 (CXCR4) and NOX during oxidative stress in PCa cells. The interaction between CXCR4 and its ligand, stromal cell-derived factor-1 $\alpha(\mathrm{SDF}-1 \alpha)$, was revealed to regulate the activity of NOX2, which leads to ROS production through the PI3K/AKT pathway. This interaction was also determined to be involved in PCa progression as it promotes cell migration that is associated with metastasis (40).

Oxidative stress acts on the tumor microenvironment and ROS have an important role in this pathway via the mTORC1/ c-Myc cascade, which is mainly controlled by p62. In the context of p62 deficiency, the stroma of the tumor is metabolically reprogrammed into a pro-tumorigenic milieu (41).
The role of oxidative stress has also been studied in CRPC, and an in vitro comparison was made between the LNCaP (hormone-sensitive) and DU145 (hormone-insensitive) cells treated with hydroxynonenal (4-HNE); 4-HNE, which is induced by oxidative stress, induces apoptosis in hormone-sensitive cells by activating p53. However, this effect was not observed in hormone-insensitive cells due to the activation of the JNK signaling pathway (42).

\section{Oxidative stress and $C P / C P P S$}

Direct toxicity of oxidative stress in CP/CPPS. Chronic prostatitis is a frequently diagnosed disease with a poorly established pathophysiology (5). The generic name encompasses various clinical entities, but the most frequent and most challenging is chronic prostatitis class NIH III, which is also known as chronic pelvic pain syndrome (5). This condition is characterized by the absence of infective etiology (43). Inflammation serves a principal role in this disease, and multiple agents of the inflammatory pathway have been studied and targeted (44). To date, oxidative stress is considered to be a significant factor in the inflammatory cascade of chronic prostatitis $(4,45)$. Only a few in vivo studies on the subject have been performed due to the highly variable patient population. The majority of studies have been conducted in vitro, with no considerable impact on clinical decision making (46-48). The available data indicate that the concentration of 8-isoprostanes, lipid-derived mediators of oxidative stress, in prostatic secretions and urine is increased among males with CP (4). Future studies exploring oxidative stress in $\mathrm{CP}$ are awaited; however, the clinical heterogeneity of these disorders renders trial design notably complicated.

Treatment of oxidative stress. As growing evidence supports the role of oxidative stress in chronic prostate diseases, investigators are struggling to explore possible therapeutic agents that can target oxidative stress (49). One must not forget that many of the foods normally consumed in the diet contain natural antioxidants. For example, blackberries, walnuts, strawberries, artichokes, cranberries, brewed coffee, raspberries, pecans, and grape juice all contain high concentrations of antioxidants per quantity served (50). Various substances have been tested for reducing the formation of ROS or increasing ROS levels enough to induce cellular apoptosis in prostatic cancerous cells (51-57). Further discussed here are the phenolic molecules and the other synthetic or natural non-phenolic options.

Phenolic molecules may act on the various processes of carcinogenesis by inducing cell apoptosis via the formation of ROS (58). Phellinus linteus is a mushroom that reduces cancer growth by increasing the toxicity of oxidative stress (53). Silibinin, a natural derivate of flavanone, reduced cell motility and invasiveness in Du145 PCa cells (54). Other phenolic molecules act by reducing the formation of ROS. Apigenin, a dietary plant flavone, is taken up by healthy prostatic cells and quickly intercalated into the DNA, thus providing protective mechanisms by reducing the formation of ROS (57). Similarly, pomegranate juice reduced PCa tumor proliferation in animal models (59). Numerous other drugs and phenolic compounds have been tested, including $\mathrm{N}$-acetylalaninate prodrugs, quercetin, Crataeva nurvala bark and seaweeds. These compounds 
were all observed to produce significant cancer cell death in in vitro and/or in vivo experiments (60-63).

Non-phenolic molecules include natural and synthetic options. Regucalcin is an intracellular calcium sensor that counteracts the aging of cells and increases the activity of apoptosis regulators in the prostate in animal models (51). Melatonin is another natural protein that increases the activity of two major intracellular enzymes, prostatic glutathione-S-transferase and glutathione peroxidase, which are characterized by their antioxidant properties (55). Omega-3 and omega- 6 fatty acids act synergistically on tumor cell survival, proliferation and angiogenesis by increasing lipid peroxidation (63). However, these biological actions may not translate into clinical significance, and require confirmation in interventional trials or observational studies with a long follow-up duration (64).

Selenium and vitamin E are the most studied antioxidants for reducing the risk of PCa by modifying the intracellular redox state, as previously described in LNCaP cell lines treated with selenium (65). The Selenium and Vitamin E Cancer Prevention Trial is one of the largest and most important studies in the chemoprevention of $\mathrm{PCa}$ to date. Male patients were enrolled and randomized into groups set to receive selenium, vitamin $\mathrm{E}$, a combination of the two or a placebo. Patients were followed for a median of 5.5 years, and the risk of developing $\mathrm{PCa}$ was evaluated. The investigators observed no significant difference in PCa risk across the four risk groups, with $4.43 \%$ of patients developing $\mathrm{PCa}$ in the placebo group, $4.56 \%$ in the selenium, $4.9 \%$ in the vitamin $\mathrm{E}$ and $4.56 \%$ in the combination arm (66). After 18 months of follow-up, the vitamin $\mathrm{E}$ arm exhibited a significantly increased risk of PCa by $17 \%$ (67). Researchers have suggested that selenium-enriched yeast, but not selenomethionine, may be effective in reducing oxidative stress. Richie et al (68) assessed the differences between the two molecules in 69 healthy males. After 9 months, levels of the oxidative stress biomarkers 8-isoprostaglandin F2 $\alpha$ and $8 \mathrm{OH}$-deoxyguanosine were reduced by 66 and $72 \%$, respectively, in patients receiving selenium-enriched yeast but not in those receiving selenomethionine. Furthermore, a key point in using selenium as a chemopreventive agent is the variability in individual responses to selenium on oxidative stress and DNA damage (69). Investigators followed 95 adults treated with selenium and noted inconsistent changes in the oxidative stress response. In addition, DNA damage was not significantly influenced by selenium treatment (69). APC-100 is the antioxidant moiety of vitamin E ( $\alpha$-tocopherol). APC-100 exhibits anti-androgenic properties, and preclinical studies have observed potent androgen receptor (AR) signaling modulation and anti-cancer activity against PCa cell lines (70). Recently, Kyriakopoulos et al (71) tested APC-100 in 20 patients with CRPC and determined that the drug was safe. PSA stabilization in these patients was a sign of drug activity despite suboptimal (71).

Other nutrients with antioxidative activity include carotenoids, ginger and curcumin compounds, and zinc (58). Lycopene is a highly unsaturated acyclic isomer of $\beta$-carotene present in red vegetables and fruits. Lycopene's effect on preventing $\mathrm{PCa}$ is debatable, with conflicting evidence (72-74). A notable prior study reported that vitamin A from animal sources increases the risk of $\mathrm{PCa}$, whereas that from plant sources decreases the risk (75). Ginger compounds suppress growth and induce apoptosis in LNCaP cells by inhibiting cyclooxygenase activity the androgen receptor; pStat 3 and $\mathrm{pPKC}(\alpha / \beta)$ pathways and the activation of the $\mathrm{p} 21$ pathway (76).

Recent studies in lipidomics and metabolomics have demonstrated that omega-3 poly-unsaturated fatty acids inhibit tumor growth directly and by modulating the immune system. These compounds mainly act by regulating multiple complex metabolic processes of oxidative stress pathways, including $\beta$-oxidation, lipid release, cellular signaling, eicosanoid synthesis, direction activation of nuclear receptors and gene transcription (77). Effectively, arachidonic acid may potentiate the risk of metastatic migration. In addition, secondary implantation may be potentiated by arachidonic acid but may also be reduced by omega-3 poly-unsaturated fatty acids (78).

The synthetic non-phenolic molecules that were tested for antioxidative effect in prostate diseases are rare. The ability of allopurinol to reduce oxidative stress has been assessed in humans; in a randomized, double-blinded study, 50 males affected with metabolic syndrome received allopurinol or placebo. A significant reduction of malondialdehyde and MPO was reported in the treatment arm (56).

\section{Conclusion}

Oxidative stress is a physiological phenomenon, but it is not yet clear which trigger mechanisms make it pathological. Evidence suggests that ROS from chronic inflammation serve a role in the pathogenesis of prostatic diseases. Due to the large number of patients who have inflammatory processes in the prostate regardless of whether the condition is symptomatic, this link is intriguing, and well-designed long-duration studies examining the effects of supplemental or dietary intake, as aforementioned, on prostate pathology, incidence, treatment and progression are required.

\section{References}

1. Lebret T, Culine S, Davin JL,Hennequin C, Mignard JP, Moreau JL, Rossi D, Zerbib M, Mahmoudi A and Latorzeff I: Quality of life of 1276 elderly patients with prostate cancer, starting treatment with a gonadotropin-releasing hormone agonist: Results of a French observational study. Aging Male 17: 87-93, 2014.

2. Siegel RL, Miller KD and Jemal A: Cancer statistics, 2016. CA Cancer J Clin 66: 7-30, 2016.

3. Aoun F, Marcelis Q and Roumeguère T: Minimally invasive devices for treating lower urinary tract symptoms in benign prostate hyperplasia: Technology update. Res Rep Urol 7: 125-136, 2015.

4. Kullisaar T, Türk S, Punab $M$ and Mändar R: Oxidative stress-cause or consequence of male genital tract disorders? Prostate 72: 977-983, 2012.

5. Aoun F, Albisinni S, Chemaly AK, Zanaty $M$ and Roumeguère T: In search for a common pathway for health issues in men-the sign of a holmesian deduction. Asian Pac J Cancer Prev 17: 1-13, 2016.

6. Bostanci Y, Kazzazi A, Momtahen S, Laze J and Djavan B: Correlation between benign prostatic hyperplasia and inflammation. Curr Opin Urol 23: 5-10, 2013.

7. Chughtai B, Lee R, Te A and Kaplan S: Role of inflammation in benign prostatic hyperplasia. Rev Urol 13: 147-150, 2011.

8. Sciarra A, Mariotti G, Salciccia S, Autran Gomez A, Monti S, Toscano V and Di Silverio F: Prostate growth and inflammation. J Steroid Biochem Mol Biol 108: 254-260, 2008.

9. Hamid AR, Umbas R and Mochtar CA: Recent role of inflammation in prostate diseases: Chemoprevention development opportunity. Acta Med Indones 43: 59-65, 2011. 
10. Wong CP, Bray TM and Ho E: Induction of proinflammatory response in prostate cancer epithelial cells by activated macrophages. Cancer Lett 276: 38-46, 2009.

11. Meagher EA and FitzGerald GA: Indices of lipid peroxidation in vivo: Strengths and limitations. Free Radic Biol Med 28: 1745-1750, 2000.

12. Merendino RA, Salvo F, Saija A, Di Pasquale G, Tomaino A, Minciullo PL, Fraccica G and Gangemi S: Malondialdehyde in benign prostate hypertrophy: A useful marker? Mediators Inflamm 12: 127-128, 2003.

13. Pace G, Di Massimo C, De Amicis D, Corbacelli C, Di Renzo L, Vicentini C, Miano L and Tozzi Ciancarelli MG: Oxidative stress in benign prostatic hyperplasia and prostate cancer. Urol Int 85 : 328-333, 2010.

14. Arsova-Sarafinovska Z, Eken A, Matevska N, Erdem O, Sayal A, Savaser A, Banev S, Petrovski D, Dzikova S, Georgiev V, et al: Increased oxidative/nitrosative stress and decreased antioxidant enzyme activities in prostate cancer. Clin Biochem 42: 1228-1235, 2009.

15. Almushatat AS, Talwar D, McArdle PA, Williamson C, Sattar N, O'Reilly DS, Underwood MA and McMillan DC: Vitamin antioxidants, lipid peroxidation and the systemic inflammatory response in patients with prostate cancer. Int J Cancer 118: 1051-1053, 2006.

16. Vital P, Castro $\mathrm{P}$ and Ittmann M: Oxidative stress promotes benign prostatic hyperplasia. Prostate 76: 58-67, 2016.

17. Massey KJ, Hong NJ and Garvin JL: Angiotensin II stimulates superoxide production in the thick ascending limb by activating NOX4. Am J Physiol Cell Physiol 303: C781-C789, 2012.

18. Verbon EH, Post JA and Boonstra J: The influence of reactive oxygen species on cell cycle progression in mammalian cells Gene 511: 1-6, 2012

19. Nassis L, Frauman AG, Ohishi M, Zhuo J, Casley DJ, Johnston CI and Fabiani ME: Localization of angiotensin-converting enzyme in the human prostate: Pathological expression in benign prostatic hyperplasia. J Pathol 195: 571-579, 2001.

20. Klebanoff SJ: Myeloperoxidase: Friend and foe. J Leukoc Biol 77: 598-625, 2005.

21. Boudjeltia KZ, Legssyer I, Van Antwerpen P, Kisoka RL, Babar S, Moguilevsky N, Delree P, Ducobu J, Remacle C, Vanhaeverbeek M and Brohee D: Triggering of inflammatory response by myeloperoxidase-oxidized LDL. Biochem Cell Biol 84: 805-812, 2006.

22. Roumeguère $\mathrm{T}$, Delree $\mathrm{P}$, Van Antwerpen $\mathrm{P}$, Rorive $\mathrm{S}$, Vanhamme L, de Ryhove Lde L, Serteyn D, Wespes E, Vanhaerverbeek $M$ and Boudjeltia KZ: Intriguing location of myeloperoxidase in the prostate: A preliminary immunohistochemical study. Prostate 72: 507-513, 2012.

23. Boudjeltia KZ, Delporte C, Van Antwerpen P, Franck T, Serteyn D, Moguilevsky N, Raes M, Vanhamme L, Vanhaeverbeek M, Van Meerhaeghe A and Roumeguère T: Myeloperoxidase-dependent LDL modifications in bloodstream are mainly predicted by angiotensin II, adiponectin, and myeloperoxidase activity: A cross-sectional study in men. Mediators Inflamm 2013: 750742, 2013.

24. Kurfurstova D, Bartkova J, Vrtel R, Mickova A, Burdova A, Majera D, Mistrik M, Kral M, Santer FR, Bouchal J and Bartek J: DNA damage signalling barrier, oxidative stress and treatment-relevant DNA repair factor alterations during progression of human prostate cancer. Mol Oncol 10: 879-894, 2016.

25. Thapa D, Meng P, Bedolla RG, Reddick RL, Kumar AP and Ghosh R: NQO1 suppresses NF-kB-p300 interaction to regulate inflammatory mediators associated with prostate tumorigenesis. Cancer Res 74: 5644-5655, 2014

26. Huang W, Eickhoff JC, Mehraein-Ghomi F, Church DR, Wilding $G$ and Basu HS: Expression of spermidine/spermine $\mathrm{N}(1)$-acetyl transferase (SSAT) in human prostate tissues is related to prostate cancer progression and metastasis. Prostate 75: $1150-1159,2015$.

27. Yang B, Wagner J, Damaschke N, Yao T, Wuerzberger-Davis SM, Lee MH, Svaren J, Miyamoto S and Jarrard DF: A nove pathway links oxidative stress to loss of insulin growth factor-2 (IGF2) imprinting through NF- $\kappa \mathrm{B}$ activation. PloS One 9: e88052, 2014.

28. Labanca E, De Luca P, Gueron G, Paez A, Moiola CP, Massillo C, Porretti J, Giudice J, Zalazar F, Navone N, et al: Association of HO-1 and BRCA1 is critical for the maintenance of cellular homeostasis in prostate cancer. Mol Cancer Res 13: 1455-1464, 2015 .
29. Basu A,Cajigas-Du Ross CK, Rios-Colon L, Mediavilla-Varela M, Daniels-Wells TR, Leoh LS, Rojas H, Banerjee H, Martinez SR, Acevedo-Martinez S and Casiano CA: LEDGF/p75 overexpression attenuates oxidative stress-induced necrosis and upregulates the oxidoreductase ERP57/PDIA3/GRP58 in prostate cancer. PloS One 11: e0146549, 2016.

30. Jin Y, Wang L, Qu S, Sheng X, Kristian A, Mælandsmo GM, Pällmann N, Yuca E, Tekedereli I, Gorgulu K, et al: STAMP2 increases oxidative stress and is critical for prostate cancer. EMBO Mol Med 7: 315-331, 2015.

31. Mian OY,Khattab MH,Hedayati M, Coulter J, Abubaker-Sharif B, Schwaninger JM, Veeraswamy RK, Brooks JD, Hopkins L, Shinohara DB, et al: GSTP1 loss results in accumulation of oxidative DNA base damage and promotes prostate cancer cell survival following exposure to protracted oxidative stress. Prostate 76: 199-206, 2016.

32. Geybels MS, van den Brandt PA, van Schooten FJ and Verhage BA: Oxidative stress-related genetic variants, pro- and antioxidant intake and status, and advanced prostate cancer risk. Cancer Epidemiol Biomarkers Prev 24: 178-186, 2015

33. Ding X, Yang DR, Lee SO, Chen YL, Xia L, Lin SJ, Yu S, Niu YJ, Li G and Chang C: TR4 nuclear receptor promotes prostate cancer metastasis via upregulation of CCL2/CCR2 signaling. Int J Cancer 136: 955-964, 2015.

34. Debelec-Butuner B, Ertunc N and Korkmaz KS: Inflammation contributes to NKX3.1 loss and augments DNA damage but does not alter the DNA damage response via increased SIRT1 expression. J Inflamm (Lond) 12: 12, 2015.

35. Chaiswing L, Zhong W and Oberley TD: Increasing discordant antioxidant protein levels and enzymatic activities contribute to increasing redox imbalance observed during human prostate cancer progression. Free Radic Biol Med 67: 342-352, 2014.

36. Yakes FM and Van Houten B: Mitochondrial DNA damage is more extensive and persists longer than nuclear DNA damage in human cells following oxidative stress. Proc Natl Acad Sci USA 94: 514-519, 1997.

37. Khandrika L, Kumar B, Koul S, Maroni P and Koul HK: Oxidative stress in prostate cancer. Cancer Lett 282: 125-136, 2009.

38. Ntais C, Polycarpou A and Ioannidis JP: Association of GSTM1, GSTT1, and GSTP1 gene polymorphisms with the risk of prostate cancer: A meta-analysis. Cancer Epidemiol Biomarkers Prev 14: 176-181, 2005.

39. Luchman HA, Villemaire ML, Bismar TA, Carlson BA and Jirik FR: Prostate epithelium-specific deletion of the selenocysteine tRNA gene Trsp leads to early onset intraepithelial neoplasia. Am J Pathol 184: 871-877, 2014.

40. Jones KJ, Chetram MA, Bethea DA, Bryant LK, Odero-Marah V and Hinton CV: Cysteine (C)-X-C receptor 4 regulates NADPH oxidase-2 during oxidative stress in prostate cancer cells. Cancer Microenviron, Sep 28, 2013 (Epub ahead of print).

41. Valencia T, Kim JY, Abu-Baker S, Moscat-Pardos J, Ahn CS, Reina-Campos M, Duran A, Castilla EA, Metallo CM, Diaz-Meco MT and Moscat J: Metabolic reprogramming of stromal fibroblasts through p62-mTORC1 signaling promotes inflammation and tumorigenesis. Cancer Cell 26: 121-135, 2014.

42. Cao ZG, Xu X, Xue YM and Zhao SL: Comparison of 4-hydroxynonenal-induced p53-mediated apoptosis in prostate cancer cells LNCaP and DU145. Contemp Oncol (Pozn) 18: 22-28, 2014.

43. Hu C, Yang H, Zhao Y, Chen X, Dong Y, Li L, Dong Y, Cui J, Zhu T, Zheng $\mathrm{P}$, et al: The role of inflammatory cytokines and ERK1/2 signaling in chronic prostatitis/chronic pelvic pain syndrome with related mental health disorders. Sci Rep 6: 28608, 2016.

44. Strauss AC and Dimitrakov JD: New treatments for chronic prostatitis/chronic pelvic pain syndrome. Nat Rev Urol 7: 127-135, 2010.

45. Polackwich AS and Shoskes DA: Chronic prostatitis/chronic pelvic pain syndrome: A review of evaluation and therapy. Prostate Cancer Prostatic Dis 19: 132-138, 2016.

46. Mosli HA, Al-Abd AM, El-Shaer MA, Khedr A, Gazzaz FS and Abdel-Naim AB: Local inflammation influences oestrogen metabolism in prostatic tissue. BJU Int 110: 274-282, 2012.

47. Wang LL, Huang YH, Yan CY, Wei XD, Hou JQ, Pu JX and Lv JX: N-acetylcysteine ameliorates prostatitis via miR-141 regulating Keap1/Nrf2 signaling. Inflammation 39: 938-947, 2016.

48. Pontari MA and Ruggieri MR: Mechanisms in prostatitis/chronic pelvic pain syndrome. J Urol 172: 839-845, 2004. 
49. Yang X, Yuan L, Xiong C, Yin C and Ruan J: Abacopteris penangiana exerts testosterone-induced benign prostatic hyperplasia protective effect through regulating inflammatory responses, reducing oxidative stress and anti-proliferative. J Ethnopharmacol 157: 105-113, 2014.

50. Halvorsen BL, Carlsen MH, Phillips KM, Bøhn SK, Holte K, Jacobs DR Jr and Blomhoff R: Content of redox-active compounds (ie, antioxidants) in foods consumed in the United States. Am J Clin Nutr 84: 95-135, 2006.

51. Vaz CV, Marques R, Maia CJ and Socorro S: Aging-associated changes in oxidative stress, cell proliferation, and apoptosis are prevented in the prostate of transgenic rats overexpressing regucalcin. Transl Res 166: 693-705, 2015.

52. Bae WJ, Ha US, Kim S, Kim SJ, Hong SH, Lee JY, Hwang TK, Hwang SY, Kim HJ and Kim SW: Reduction of oxidative stress may play a role in the anti-inflammatory effect of the novel herbal formulation in a rat model of hydrochloric acid-induced cystitis Neurourol Urodyn 34: 86-91, 2015.

53. Konno S, Chu K, Feuer N, Phillips J and Choudhury M: Potent anticancer effects of bioactive mushroom extracts (Phellinus linteus) on a variety of human cancer cells. J Clin Med Res 7: 76-82, 2015.

54. Prajapati V, Kale RK and Singh RP: Silibinin combination with arsenic strongly inhibits survival and invasiveness of human prostate carcinoma cells. Nutr Cancer 67: 647-658, 2015.

55. Gobbo MG, Costa CF, Silva DG, de Almeida EA and Góes RM: Effect of melatonin intake on oxidative stress biomarkers in male reproductive organs of rats under experimental diabetes. Oxid Med Cell Longev 2015: 614579, 2015.

56. Yiginer O, Ozcelik F, Inanc $\mathrm{T}$, Aparci $\mathrm{M}$, Ozmen $\mathrm{N}$, Cingozbay BY, Kardesoglu E, Suleymanoglu S, Sener G and Cebeci BS: Allopurinol improves endothelial function and reduces oxidant-inflammatory enzyme of myeloperoxidase in metabolic syndrome. Clin Res Cardiol 97: 334-340, 2008

57. Sharma H, Kanwal R, Bhaskaran N and Gupta S: Plant flavone apigenin binds to nucleic acid bases and reduces oxidative DNA damage in prostate epithelial cells. PloS One 9: e91588 2014.

58. Anantharaju PG, Gowda PC, Vimalambike MG and Madhunapantula SV: An overview on the role of dietary phenolics for the treatment of cancers. Nutr J 15: 99, 2016.

59. Gueritat J, Lefeuvre-Orfila L, Vincent S, Cretual A, Ravanat JL, Gratas-Delamarche A, Rannou-Bekono F and Rebillard A: Exercise training combined with antioxidant supplementation prevents the antiproliferative activity of their single treatment in prostate cancer through inhibition of redox adaptation. Free Radic Biol Med 77: 95-105, 2014.

60. McGoldrick CA, Jiang YL, Brannon M, Krishnan K and Stone WL: In vitro evaluation of novel $\mathrm{N}$-acetylalaninate prodrugs that selectively induce apoptosis in prostate cancer cells. BMC Cancer 14: 675, 2014.

61. Kumar DG, Deepa P, Rathi MA, Meenakshi P and Gopalakrishnan VK: Modulatory effects of Crataeva nurvala bark against testosterone and $\mathrm{N}$-methyl-N-nitrosourea-induced oxidative damage in prostate of male albino rats. Pharmacogn Mag 8: 285-291,2012.

62. Ratnayake R, Liu Y, Paul VJ and Luesch H: Cultivated sea lettuce is a multiorgan protector from oxidative and inflammatory stress by enhancing the endogenous antioxidant defense system. Cancer Prev Res (Phila) 6: 989-999, 2013.

63. Yonezawa Y, Hada T, Uryu K, Tsuzuki T, Eitsuka T, Miyazawa T, Murakami-Nakai C, Yoshida H and Mizushina Y: Inhibitory effect of conjugated eicosapentaenoic acid on mammalian DNA polymerase and topoisomerase activities and human cancer cell proliferation. Biochem Pharmacol 70: 453-460, 2005.
64. Lovegrove C, Ahmed K, Challacombe B, Khan MS, Poper R and Dasgupta P: Systematic review of prostate cancer risk and association with consumption of fish and fish-oils: Analysis of 495,321 participants. Int J Clin Pract 69: 87-105, 2015.

65. Flis A, Suchocki P, Królikowska MA, Suchocka Z, Remiszewska M, Sliwka L, Książek I, Sitarz K, Sochacka M, Hoser G, et al: Selenitetriglycerides-Redox-active agents. Pharmacol Rep 67: 1-8, 2015.

66. Lippman SM, Klein EA, Goodman PJ, Lucia MS, Thompson IM, Ford LG, Parnes HL, Minasian LM, Gaziano JM, Hartline JA, et al: Effect of selenium and vitamin E on risk of prostate cancer and other cancers: The selenium and vitamin e cancer prevention trial (SELECT). JAMA 301: 39-51, 2009.

67. Klein EA, Thompson IM Jr, Tangen CM, Crowley JJ, Lucia MS, Goodman PJ, Minasian LM, Ford LG, Parnes HL, Gaziano JM, et al: Vitamin E and the risk of prostate cancer: The selenium and vitamin E cancer prevention trial (SELECT). JAMA 306: 1549-1556, 2011.

68. Richie JP Jr, Das A, Calcagnotto AM, Sinha R, Neidig W, Liao J, Lengerich EJ, Berg A, Hartman TJ, Ciccarella A, et al: Comparative effects of two different forms of selenium on oxidative stress biomarkers in healthy men: A randomized clinical trial. Cancer Prev Res (Phila) 7: 796-804, 2014.

69. Jablonska E, Raimondi S, Gromadzinska J, Reszka E, Wieczorek E, Krol MB, Smok-Pieniazek A, Nocun M, Stepnik M, Socha K, et al: DNA damage and oxidative stress response to selenium yeast in the non-smoking individuals: A short-term supplementation trial with respect to GPX1 and SEPP1 polymorphism. Eur J Nutr 55: 2469-2484. 2016.

70. Thompson TA and Wilding G: Androgen antagonist activity by the antioxidant moiety of vitamin E, 2,2,5,7,8-pentamethyl6-chromanol in human prostate carcinoma cells. Mol Cancer Ther 2: 797-803, 2003.

71. Kyriakopoulos CE, Heath EI, Eickhoff JC, Kolesar J, Yayehyirad M, Moll T, Wilding G and Liu G: A multicenter phase $1 / 2$ a dose-escalation study of the antioxidant moiety of vitamin E 2,2,5,7,8-pentamethyl-6-chromanol (APC-100) in men with advanced prostate cancer. Invest New Drugs 34: 225-230, 2016.

72. Giovannucci E, Ascherio A, Rimm EB, Stampfer MJ, Colditz GA and Willett WC: Intake of carotenoids and retinol in relation to risk of prostate cancer. J Natl Cancer Inst 87: 1767-1776, 1995.

73. Albanes D, Heinonen OP, Huttunen JK, Taylor PR, Virtamo J, Edwards BK, Haapakoski J, Rautalahti M, Hartman AM, Palmgren J, et al: Effects of alpha-tocopherol and beta-carotene supplements on cancer incidence in the alpha-tocopherol beta-carotene cancer prevention study. Am J Clin Nutr 62 (6 Suppl): 1427S-1430S, 1995.

74. Norrish AE, Jackson RT, Sharpe SJ and Skeaff CM: Prostate cancer and dietary carotenoids. Am J Epidemiol 151: 119-123, 2000.

75. Kolonel LN, Nomura AM and Cooney RV: Dietary fat and prostate cancer: Current status. J Natl Cancer Inst 91: 414-428, 1999.

76. Bemis DL, Capodice JL, Anastasiadis AG, Katz AE and Buttyan R: Zyflamend, a unique herbal preparation with nonselective COX inhibitory activity, induces apoptosis of prostate cancer cells that lack COX-2 expression. Nutr Cancer 52: 202-212, 2005

77. Gu Z, Suburu J, Chen H and Chen YQ: Mechanisms of Omega-3 polyunsaturated fatty acids in prostate cancer prevention. Biomed Res Int 2013: 824563, 2013.

78. Brown MD, Hart CA, Gazi E, Bagley S and Clarke NW: Promotion of prostatic metastatic migration towards human bone marrow stoma by Omega 6 and its inhibition by Omega 3 PUFAs. Br J Cancer 94: 842-853, 2006. 